\title{
Using the IDEA model to analyze messages used in Hepatitis B vaccination in Uganda
}

\author{
Ann Mugunga \\ Hong Kong Baptist University \\ Kowloon, Hong Kong \\ Angella Napakol \\ Uganda Christian University \\ Mukono, Uganda
}

\begin{abstract}
This research analyzed the messages that both the Government of Uganda and the National organization of persons living with Hepatitis B use to communicate to at-risk populations in order to enable them take up the vaccination against Hepatitis B. Content analysis was carried out on two electronic fliers circulated from the ministry of health's program in charge of Hepatitis control and treatment, and one hard copy flier from the National organization of persons living with Hepatitis B. The study assessed how the publications made use of the IDEA concepts of internalization, distribution, explanation and action in getting the audience to take up the vaccination against Hepatitis B. The findings are relevant to information, education and communication message initiators in the health sector, as they underline the importance of clear messages, distributed in various channels and available in many languages.
\end{abstract}

Keywords - IDEA model, message clarity, Hepatitis B, vaccination

SUGGESTED CITATION: Mugunga, A., \& Napakol, A. (2020). Using the IDEA model to analyse messages used in Hepatitis B vaccination in Uganda. Proceedings of the International Crisis and Risk Communication Conference, Volume 3 (pp. 33-36). Orlando FL: Nicholson School of Communication and Media. https://www.doi.org/10.30658/icrcc.2020.8

\section{INTRODUCTION}

National health institutions have historically, with the help of the World Health Organisation sought to reduce risk of disease spread by carrying out vaccination campaigns and other health enhancing processes that ensure the physical wellbeing of their communities [1]. Hepatitis B is a "contagious liver infection caused by the hepatitis B virus (HPV) which enters the body through blood-to-blood contact" [2]. The disease manifests differently from one person to another depending on the stage of infection of a particular person. When an individual is first infected with Hepatitis B, there are usually no signs of the disease and it is possible for it to go undetected. This stage is known as "acute hepatitis B infection" [2]. While the immune systems of $90 \%$ of adults who get infected with the Hepatitis B virus are able to fight it off successfully, $10 \%$ of those infected remain with the disease for the rest of their lives, thus having what it clinically known as "chronic hepatitis B infection [2]. Chronic hepatitis B infection exposes those affected to various health complications including abnormal functioning of the liver, and disrupts the general quality of life. There is also high possibility of the disease being passed on to unborn babies and sexual partners, among others who come into contact with their blood.

Uganda is one of the countries with the highest prevalence levels of Hepatitis B. According to the Ministry of HealthUganda, 3.5 million people (10\% of population) are living with chronic Hepatitis B infection. The country's general population has a $52 \%$ lifetime chance exposure; one of the highest in the world. In spite of this, 9 out of every 10 people do not know their Hepatitis B status [3]. The high risk to Hepatitis B exposure among the population led to the 2014 'Public Health Declaration of Hepatitis B as a formidable epidemic disease order', and the 'Vaccination of Health Workers against Hepatitis B virus rules' [4]. These rules required all health workers be vaccinated aganist the virus. The country's vaccination efforts are spearheaded by the Hepatitis B Taskforce [3].

At the same time that these rules were put in place, the national testing and vaccination campaign against Hepatitis B was rolled out. The country's minister of health said that by July 2018 over 2 million people tested negative for Hepatitis $\mathrm{B}$ and were initiated on the vaccination program [4]. These qualified for the vaccine, and the turn-up for the first dose was $91.7 \%$, the turn-up for the second dose was $68 \%$ and the turn-up for the third dose dropped to $33 \%$ [4]. This challenge requires an understanding of the instructional messages as communicated to the at-risk-communities. This 
study focused on the messages circulated by both the ministry of health and the national association of persons living with Hepatitis B. A qualitative thematic analysis was conducted based on the messages that are available, with no inclusion of message designers' perspective. The analysis assessed whether the messages are effectively packaged, as per the elements in the IDEA model, to enable individuals deal with the risk of Hepatitis B.

\section{LITERATURE REVIEW}

It has been argued that for communication to be effective, there should be decoding, or making sense of a message by the recipient. Studies have been conducted into the role played by clear messages in ensuring greater buy-in and positive response by clients to the product or service of a company [5]; and that when a message provides data for the claim that it is making, without inundating the audience with many figures but providing non-intimidating data, then it is perceived as a clear and effective message [6]. Further, Kim \& Bae, 2016 contend that presenting a message that is clear increases the possibility that it will be well received by the target audience. In situations of risk for example possible exposure to Hepatitis, research shows that people need occasional, clear information that they can relate to and which provides them with simple and easily understandable instructions about what to do to protect themselves and their loved ones, proving that effective communication is vital for instruction in risk situations [7].

This research was grounded in the IDEA Model of effective instructional risk and crisis message presentation [7]. The model is based on the experiential learning theory as first conceived by John Dewey (1938), then extended by David Kolb (1984) and its components are internalization (helping those who receive risk communication messages to understand them in the context of the potential risk that is posed to them, or in a way that makes sense to them and which they can conceptualize and relate to personally) distribution (making sure that the channels through which the risk or crisis message has been disseminated is relevant to the target audience) explanation (giving simple, clear and nonscientific explanations of the health risk) and action (providing clear instructions on what those who are at risk can do to avert the situation or guard themselves against the situation). In this research, the model was "utilized to assess perceived message effectiveness" [7].

Although there are other factors such as self eficicacy that could contribute to the uptake and completion of the Hepatitis B 3-dose vaccination, this research focuses only on the communication aspect. Specifically, the messages used in the prevention and treatment of Hepatitis B were analysed against the IDEA model elements of internalization, distribution, explanation and action. The aim is to provide an analysis of how messages can be best presented to spur targeted audiences to intended action. The following questions guided the study: 1. How do the fliers studied make use of internalization? 2. How do the fliers use the element of explanation? 3. How do the fliers use the element of action and finally, 4. How do the fliers make use of exemplification to achieve internationalisation?

\section{PROCEDURES}

A thematic analysis of the content was carried out on the three sets of fliers (two) carried by both Ministry of Health and one from the National Association of People Living with Hepatitis B in Uganda. The Ministry of Health in Uganda has a program in charge of Hepatitis control and treatment, and the institution's website carries the following fliers: "What is Hepatitis"; What is Hepatitis B"; "How does Hepatitis C spread"; "Hepatitis B: What you need to know", "How does Hepatitis A spread". The national association of people living with Hepatitis B also has a distribution flier called the "Hepatitis B fact sheet". These fliers are given out at the organization offices and also during outreach and community engagement sessions. The fliers can mostly be accessed on the ministry's website and some health centers download for distribution to the health care givers. According to the Health Promotion Officer in the Ministry of Health, “...more materials were prepared but they have not been disseminated. They are still in soft copy and we lack the resources to produce and distribute them," he said when contacted about availability of more resources apart from the online fliers.

The national organization of persons living with Hepatitis B is a non-governmental organization started in 2011 in Uganda, to advocate for the rights of Hepatitis patients and create awareness about the disease. It makes available a flier in hard copy form, to sensitize at-risk communities about the disease.

\section{RESULTS}

RQ1a. How does the 'What is Hepatitis B' flier circulated by the Ministry of Health, Uganda make use of the internalization? In order to understand how the element of internalization in the IDEA model was used in the 'What is Hepatitis B' flier, the content was analyzed for compassion, personal relevance, proximity, timeliness and exemplification. It was noted that the flier did not capture any of these elements but instead offered scientific information about Hepatitis, with no mention of how the affected patients should be treated, or how close the threat of the viral disease is to the reader. Also, there were no negative or positive exemplars to enable the message recipients remember it for longer.

RQ1b. How does the 'What is Hepatitis B' flier circulated by the Ministry of Health, Uganda make use of 
explanation? In terms of explanation, the flier simply said that Hepatitis is 'a viral infection that causes inflammation of the liver', alluding to the possibility that the audience knows what inflammation of the liver is, or that this is a situation that is exclusively caused by Hepatitis, which might not be the case. Further, there were at least five medical term abbreviations in the flier, which was not longer than two paragraphs. The fourth point read, "Chronic hepatitis may progress to cause liver cirrhosis and liver cancer thus accounting for most of the burden of disease". All these are medical terms with no intelligent, lay man explanation so the reader might not clearly understand what this is all about. 'Liver cirrhosis' and 'burden of disease' are not pedestrian terms that are used by a lay man to describe a situation and so they may not understand what the flier is about.

RQ1c. How does the 'What is Hepatitis B' flier circulated by the Ministry of Health, Uganda make us of action? The action element in the flier was the focus on the toll free number that was provided at the end. Although the number was clearly displayed in the lower right hand corner of the flier, it was the only action point with no website, email address or any other contact alternatives.

RQ1d. How does the "What is Hepatitis B' flier circulated by the Ministry of Health make use of exemplification in communicating internalization, explanation and action in order to emphasize the importance of taking the Hepatitis B vaccination in the country? The "What is Hepatitis" flier did not employ exemplification, negative or positive. It simply provided the medical terms used to describe hepatitis, and gave the toll free number with no attempt at exemplification to get the attention of the audience.

RQ2a. How does the "Hepatitis B: What you need to know" flier circulated by the Ministry of Health, Uganda make use of the internalization? The goal of internalization is "to get attention and aid retention" p.158 [7]. The "Hepatitis B: What you need to know' flier from the ministry of health had elements of internalization by reflecting the groups of people who are susceptible to infection in the section of how the disease spreads. Individuals can identify the behavior or categories of actions that would expose them to infection, for example from infected mother to new born baby, sharing sharp objects and sexual intercourse with an infected person. It went ahead to list the possible symptoms of the disease which pointed to severity of consequences of contracting Hepatitis B.

RQ2b. How does the "Hepatitis B: What you need to know" flier circulated by the Ministry of Health, Uganda make use of explanation? This flier contained more elements of explanation. Although it was not detailed on the explanation of what the disease is, it outlined the treatment process for Hepatitis B stating clearly that "not everyone who tests positive for Hepatitis B qualifies for treatment" and that "additional tests have to be carried out to determine whether treatment is needed". It also clearly outlined the places where the public could access treatment services.

RQ2c. How does the "Hepatitis B: What you need to know" flier circulated by the Ministry of Health, Uganda make use of action? On the element of action, the flier section of "where to get services" was carried in one-third of the print out message and this informed the receivers of the message that they could access services at all public health care facilities free of charge. There was however no indication of further message sources for example phone lines or websites that could be accessed for more information.

RQ2d. How does the "Hepatitis B: What you need to know" flier circulated by the Ministry of Health make us of exemplification in communicating internalization, explanation and action in order to emphasize the importance of taking the Hepatitis B vaccination in the country? The flier did not make any use of positive or negative exemplification to get the attention of the audience.

RQ3a. How does the "Hepatitis B fact Sheet" circulated by the National Organisation for People Living with Hepatitis B in Uganda make use of the internalization? This flier contained elements that focused on internalization by carrying various sections that defined what would otherwise be clinical concepts of the illness. It has sections on "what is hepatitis B' the 'mode of spread' as well as 'signs and symptoms'. It further went ahead to debunk some myths by stating that 'Hepatitis B will not spread by greeting, touching, sharing utensils or eating with an infected person'.

RQ3b. How does the "Hepatitis B fact Sheet" circulated by the National Organisation for People Living with Hepatitis B in Uganda make use of explanation? Those that access and read the flier will also be able to get the layman explanation of the difference between acute and chronic Hepatitis B. It is indicated that 'acute hepatitis refers to the disease lasting not more than 6 months in the body of a person after they have been infected'. It also provided the explanation that 'some people recover from acute infection and so they will not spread it to others ... for others the infection remains in the body and leads to a lifelong chronic infection'. Further explanation was cemented by the section on 'how can you prevent transmission' - which outlined the importance of vaccination for those who test negative, as well as behavioral practices to avoid to prevent infection. It however, did not indicate the sources of medical assistance or where people could go to get medical help for vaccination and testing.

RQ3c. How does the "Hepatitis B fact Sheet" circulated by the National Organisation for People Living with Hepatitis B in Uganda make us of action? The section on 'what you should do' outlined the actions that could be taken by those who accessed the flier. It begins with 'Gate (sic) tested to know your status' and further outlines what individuals should do, with guidelines on the way forward for those who test positive as well as those who test negative for the virus. The section $\mathrm{n}$ 'what happens when a family member tests positive' also included action elements of what individuals could do in case those they know are affected.

RQ3d. How does the "Hepatitis B fact Sheet" circulated by the National Organisation for People Living with Hepatitis B in Uganda make us of exemplification in communicating internalization, explanation and action in order to 
emphasize the importance of taking the Hepatitis B vaccination in the country? The flier did not make use of either positive or negative exemplification in its presentation. The chairperson of the organization said that he wouldn't even recommend the flier, since radio is a better way to disseminate information to the communities in Uganda.

\section{DISCUSSION}

Although the toll free number was clearly displayed in the lower right hand corner of the "What is Hepatitis' flier, it was the only action point with no website, email address or any other contact alternatives. This is assuming that all those who come into contact with this information have access to a phone line.

The "What is Hepatitis B" flier did not make any use of positive or negative exemplification to get the attention of the audience. This makes the information provided remote, non-relatable and the audience could possibly get no connection to the message as it could be seen as a distant reality that has no bearing on individual current or future circumstances since they cannot identify themselves in the presentation. None of the fliers make use of exemplification, making this a distant, remote possibility in a country where adults have a $52 \%$ life time possibility of contracting of the disease. This is especially worrying given that the disease is asymptomatic and the at-risk communities are already averse to getting a vaccine because they do not see the disease as an immediate threat, so if there is no exemplification, this further plays into their justification of the threat being a distant concern that is not even affecting anyone they know or can relate to. Research has shown that exemplification makes a health communication more relatable and follow up action is easier on the audience [8].

These findings are crucial for information and communication message producers in health sector, as they underline the fact that they should improve on the internalization, explanation, distribution and action aspects of the messages to make them more effective in encouraging at-risk communities to take up the Hepatitis B vaccination.

\section{CONCLUSION}

There is considerable research to suggest that people search for information in various ways from various media so it is critical for public information or risk communication to be relayed in various means. This research indicated that the messages provided by the ministry of health Uganda as well as those from the association of the people living with Hepatitis B are only circulated using fliers, and in English. In the country, while English is one of the two national languages, the other being Swahili, and the most widely spoken of the two, the majority of the population is literate in their local languages. The country has 53 local languages so those who are not literate in English are left out of the possibility of accessing information about the prevention, treatment and care for Hepatitis B.

\section{Author Biography}

Ann Mugunga: MA, University of Leeds, UK; PhD Student, Hong Kong Baptist University, Hong Kong. Ann.mugunga@gmail.com

Angella Napakol: PhD, University of KwaZulu Natal, South Africa, Head of Communication Department, Uganda Christian University. Angella.Napakol@gmail.com

\section{REFERENCES}

[1] Leppo, K., Ollila, E., Peña, S., Wismar, M. \& Cook, S. (2013). Health in all policies: Seizing opportunities, implementing policies. Available at https://bit.ly/2LinoHh

[2] Population Health Division, San Francisco Department of Public Health, USA. (2019). What is Hepatitis B? www.sfcdcp.org

[3] Magezi, L. N. (08 November 2017) Hepatitis B: Why you should get tested. New Vision online at www.newvision.co.ug

[4] Ministry of Health, Uganda website https://health.go.ug/content/what-hepatitis-b

[5] Kim, S., and Bae, J. (2016). Cross-cultural differences in concrete and abstract corporate social responsibility (CSR) campaigns: perceived message clarity and perceived CSR as mediators. International Journal of Corporate Social Responsibility, 1, 6. https://doi.org/10.1186/s40991-016-0009-1

[6] Yalch, R. F., \& Elmore-Yalch, R. (1984). The Effect of Numbers on the Route to Persuasion. Journal of Consumer Research, 11, 522-527. https://doi.org/10.1086/208988

[7] Sellnow, D. D., Lane, D. R., Sellnow, T. L., and Littlefield, R. S. (2017). The IDEA Model as a Best Practice for Effective Instructional Risk and Crisis Communication. Communication Studies, 68, 552-567. https://doi.org/10.1080/10510974.2017.1375535

[8] Zillmann, D. (2006) Exemplification effects in the promotion of safety and health. Journal of Communication, 56 (s1), 221-237. https://doi.org/10.1111/j.1460-2466.2006.00291.x 